To be cited as: Di Ronco, A. (2016). Public drunkenness as a nuisance in Ghent

(Belgium) and Trento (Italy). Crime, Law \& Social Change. DOI: 10.1007/s10611-016-

9624-8 (first online: 9 June 2016).

\title{
Public drunkenness as a nuisance in Ghent (Belgium) and Trento (Italy)
}

\begin{abstract}
This article explores the reality of the nuisance of public drunkenness in one nightlife location of Ghent (Belgium) and in one of Trento (Italy) and inspects the way alcohol-related disorder is viewed and tackled by police officers there. Drawing on the literature arguing for the existence of different "cultures of drinking" in western and southern European countries, a distinct reality of the nuisance of public drunkenness was hypothesized to be present in these two cities. Against the backdrop of cultural criminology scholarship and of the national literature on policing practices, it was expected that the physical/aesthetic appearance of street drinkers would differently impact on the way police officers there represent alcohol-related disorder and enforce national and local nuisance regulations. The gathered data indicate that while drinking patterns and connected disorderly behavior do not significantly vary in Ghent and in Trento, the aesthetic/physical characteristics of certain groups of people play a role in shaping the representations of some police officers in Trento. The study concludes that cultural and context-specific factors, including those linked to the cultures of drinking and to aesthetics, should be considered in criminological research to more fully understand and explain the different policing views on and attitudes to alcohol-related disorder in inner-city nightlife areas. In its conclusions, the article also highlights some directions for future research.
\end{abstract}

\section{Introduction}

Alcohol plays a fundamental social and cultural role in all European societies. When used in moderation, it often facilitates social interaction and reinforces community ties (Anderson and Baumberg, 2006). Such roles, however, may have been shaped differently across countries (Mandelbaum, 1965) or, more accurately, within different sociocultural contexts (Gordon et al., 2012). In different cultures, the symbolic meanings that are associated with the activity of drinking may vary according to a number of factors: the type of alcoholic beverage that is consumed, the time and space within which consumption takes place, along with the level of intoxication and the purpose (if any) of consumption (e.g., getting drunk, as opposed to drinking with friends in casual venues). Furthermore, specific societal expectations (Heath, 1995) that shape the way people are supposed to behave and appear in public places, contribute to identifying socially acceptable drinking, as opposed to 
drunken behaviour. As suggested by some authors (MacAndrew and Edgerton, 1969; Heath, 1998; Room, 2001), drunken behaviour is, indeed, a notion whose definition may vary from one culture to another.

According to the Oxford Dictionaries, a drunk is a person "affected by alcohol to the extent of losing control of one's faculties or behaviour". Drunk connected to disorderly, moreover, refers to the activity of "[c]reating a public disturbance under the influence of alcohol", ${ }^{1}$ where disturbance is understood as the "interruption of a settled and peaceful condition". ${ }^{2}$ The (short-term) effects of excessive alcohol consumption may be several and affect an individual both physically and behaviourally. ${ }^{3}$ They include headache, nausea, vomiting, lack of coordination, loss of inhibition, intense moods and so forth. ${ }^{4}$ Such effects may be viewed differently by people depending on the socio-economic context they are living in: by some individuals and cultures they may be regarded as disorderly and anti-social, by some others they may be understood as a normal and tolerated behaviour (at least, when it occurs in certain times and spatial settings).

Societal attitudes to public drinking and drunkenness may also vary according to the urban areas where they occur. In the UK, the inner-city areas where licensing venues are concentrated are often associated in the literature on the Night-Time Economy (NTE) with the occurrence of episodes of violence and aggression (Hobbs, 2003; Hobbs et al., 2003, 2005; Graham and Homel, 2008) and, more generally, of social and physical disorder. For the production of disorderly behaviour, street drinking has often been described as a contested activity in such urban areas, leading sometimes local policy-makers to adopt punitive law, enforced by agencies of formal control. ${ }^{5}$ The attitudes of drinkers, the public, and of law enforcers to public drinking in inner-city nightlife locations may, however, vary (and be more positive) in different sociocultural settings (Demant and Landolt, 2013). ${ }^{6}$

\footnotetext{
${ }^{1}$ See http://www.oxforddictionaries.com/us/definition/american_english/drunk.

${ }^{2}$ See http://www.oxforddictionaries.com/definition/english/disturbance.

${ }^{3}$ Such affects are usually measured in terms of units of consumption. According to Jayne and colleagues (2012: 829 ), however, such units fail to (among others) attend to the "emotional, embodied and affective geographies" of alcohol drinking and drunkenness, which are also thought to play a role in the individuals' engagement in alcohol-related violence and disorder (Jayne and Valentine, 2016). Such units, moreover, seem to also be relatively neglected by drinkers in their personal assessment of alcoholic consumption and intoxication (Jayne et al., 2012). For a critical account of the use of units to measure individuals' levels of intoxication, see Jayne et al. (2012).

${ }^{4}$ See http://www.drinkwise.org.au/you-alcohol/alcohol-and-your-health/effects-of-alcohol/.

${ }^{5}$ Research in the NTE has also critically addressed the policies adopted in the UK and in many UK cities aimed at the control of alcohol-related disorder. See (among others) Chatterton and Hollands (2003), Hobbs et al. (2003), Hayward and Hobbs (2007) and Crawford and Flint (2009).

${ }^{6}$ In their research on youth drinking in Zurich (Switzerland), Demant and Landolt (2013: 2) found that street drinking is more "accepted" in areas surrounded by bars and clubs rather than in places where such venues are absent.
} 
Depending on the roles that the activity of drinking plays in different cultures and on the way public drinking and drunkenness in nightlife locations are viewed by populations, a different (formal and informal) response to public drunkenness may also be adopted (Mandelbaum, 1965; MacAndrew and Edgerton, 1969; Jayne et al., 2008b). To investigate and explain differences (along with similarities) in the practices and processes of drinking in urban public spaces across localities, regions and countries, and in the meanings assigned to urban drinking by different societal groups, Jayne and colleagues (2006) have emphasized the importance of using ethnographic research methods.

Through an ethnographic comparative study, this article aims, firstly, to explore the nuisance of public drunkenness in two nightlife locations of Ghent (Belgium) and of Trento (Italy). To identify the public spaces, time-frames, and situational circumstances that make public drinking a nuisance in these two cities, it will rely on the results of semi-structured interviews with police officers and on systematic observations carried out in two of the cities' nightlife locations. Secondly, based on interviews with local police officers, this article will inspect the way public drunkenness is viewed by law enforcement actors and the degree to which local nuisance regulations are enforced by them. Thirdly, an attempt will be made to explain eventual differences in the representations and enforcement of the nuisance of public drunkenness in light of some country- or city-specific cultural factors.

\section{Methodology}

The present ethnographic study is based on the "immersion" of the researcher in a specific "socio-cultural context" (Travers et al., 2013: 463), which in the study corresponds to two nightlife locations situated in two cities, one located in Belgium (Ghent) and one in Italy (Trento). It has an exploratory character as it aims is to explore, through observations in these particular settings, the drinking practices adopted, and the significance assigned to them, by people there. Furthermore, it also aims to explore how police officers see and tackle the nuisance of public drunkenness in those areas through the carrying out of interviews with them. ${ }^{7}$ As put it by Tedlock (2003: 190), "by entering into first-hand interaction with people in their everyday lives, ethnographers

\footnotetext{
${ }^{7}$ Although in the study we focused on police officers' representations (which were captured through the holding of interviews with them), we were not only interested in their views on, and enforcement attitudes to, drinking and drunkenness in night-time locations. The research focus was also (indirectly) on the dominant societal meanings assigned to drinking and drunkenness, as reflected in the views of police agents. Furthermore, we also investigated dominant societal views on drinking and drunkenness in the selected night-life locations by inquiring, during the systematic observations, bar owners, passers-by, and street drinkers through informal interviews (see the section of this article dedicated to "Results").
} 
can reach a better understanding of the beliefs, motivations, and behaviour of their subjects than they can by using any other method".

This ethnographic research also aims to fulfil explanatory purposes. By empirically testing two hypotheses, which have deductively been derived from theory at the outset of the study, it attempts to provide an explanation for (expected) different realities of alcohol-related disorder in two cities' nightlife locations and for (expected) different police representations of, and enforcement responses to, it in the same areas. However, in light of its (main) exploratory nature, the study also relies on an inductive approach, which, during the phases of data collection and of data analysis, allows to be open to, and to capture, new or rival sources of explanation for the social phenomena under study. ${ }^{8}$

\section{Hypotheses}

It is firstly hypothesised that a different reality of the nuisance of public drunkenness exists in Ghent (Belgium) and Trento (Italy), and that such a difference can be explained against the backdrop of a different "cultures of drinking", which are assumed to vary in four elements (see below). Secondly, it is hypothesised that the aesthetic characteristics of certain individuals and groups differently impact on police officers' representations of the nuisance of public drunkenness, and on their enforcement responses to it, in the two selected cities' nightlife locations.

Culture of drinking. In the literature on the topic, the drinking behaviours and habits of southern Europeans are usually opposed to those adopted by people living in "the rest" (Järvinen and Room, 2007: 2) of Europe, meaning in western, eastern and northern European countries. First, drinking patterns differ in the type of alcoholic beverages that are mostly consumed: while in middle ${ }^{9}$ parts of Europe people are said to prefer to drink beer, in the southern parts of the region wine appears to be the most widespread type of beverage (Järvinen and Room, 2007). ${ }^{10}$ Second, drinking customs differ in their modes and frequency: in the "dry" cultures of the north and central parts of Europe, a low frequency in the consumption of alcoholic drinks is often associated with heavy states of intoxication, whereas in the "wet" cultures of the south the consumption of alcohol, although

\footnotetext{
${ }^{8}$ The combination of deductive and inductive approaches in qualitative research has been regarded by Patton (2002: 493-4) as "analytic induction".

9 Järvinen and Room (2007) speak about "beer cultures" when referring to the drinking habits of both Western and Central European countries. They oppose such cultures to the so-called "spirit cultures" widespread in the area of the North Baltic and in Eastern Europe, and to the "wine cultures" of the south of Europe.

${ }^{10}$ Anderson and Baumberg (2006) argued for a homogenisation in students' drinking preferences in some parts of Europe. Conflicting evidence has, however, been provided by Mäkelä and colleagues (2006), who confirmed the regional differences in beverage-specific frequency of drinking.
} 
being regular, is usually considered as moderated (Plant and Miller, 2001; Anderson and Baumberg, 2006; Calafat et al., 2010). ${ }^{11}$

Traditionally, binge drinking is said to be more prevalent among adolescents and youngsters living in the "dry" cultures of the north and eastern parts of Europe (Kuntsche et al., 2004; Landberg, 2012), who are also more prone to engage in violent and problematic behaviour when inebriated from alcohol (Room and Rossow, 2001; Felson et al., 2011). Although Felson et al. (2011) evidenced that the link between alcohol and violence is less prominent in central ${ }^{12}$ Europe than in Nordic and eastern countries, such an effect is higher there than in the Mediterranean countries (where drinking is found to have a spurious effect on adolescent violence). High levels of intoxication have also been associated with the adoption of disorderly behaviour (Richardson and Budd, 2003).

It is hypothesised that different cultures of drinking are present in cities situated in western European countries, such as in Belgium, and in cities located in the countries in the southern part of the region, like Italy. The existence of different drinking cultures in two cities adhering, the first, to the "dry" drinking culture, and, the second, to the "wet" drinking culture, is to be tested by taking into consideration four different elements of the "wet-dry" dichotomy (Room and Mäkelä, 2000): 1) the frequency and duration of consumption; 2) the type of drink consumed; 3) the level of alcoholic intoxication; and 4) the adoption of violent and disorderly behaviour. On the basis of these four elements, it is hypothesised that in Ghent the consumption of beer (despite being occasional) involves long(er) consumption times, as well as high levels of intoxication and of disorderly behaviour. In Trento, by contrast, a regular-type of drinking is expected to occur in the hours preceding midnight and to involve the moderate consumption of wine.

\footnotetext{
11 A number of studies have questioned the validity of the distinction between "dry" and "wet" cultures, suggesting that there has been an homogenisation in the drinking patterns of Europeans (Room and Mäkelä, 2000; Anderson and Baumberg, 2006; Mäkelä et al., 2006; Gordon et al., 2012). Research in the UK also indicates that the differences between the "British binge drinking" and what is perceived to be the "European", "continental", or "Mediterranean" more "civilized" way of drinking (which have informed national and local policies aimed at the reduction of alcohol-related disorder), has recently started to fade (Jayne et al., 2008a). As argued by Jayne and colleagues (2008a), for example, British drinkers have a complex understanding of their drinking behaviour, which is sometimes thought to fall within the British way of (binge) drinking and sometimes within the "European" (civilised) way (when the purpose of drinking is socialisation, rather than drunkenness). A few studies also argued for an overall increase in drunkenness in Europe, with people in the southern countries adopting a "Nordic" type of (binge) drinking (Järvinen and Room, 2007; Gilligan et al., 2012). However, despite reporting increasing levels of alcohol consumption in southern countries like Spain, research has also shown that people there tend to reach only moderate levels of intoxication (see Huges et al., 2011).

${ }^{12}$ In this study Belgium has been considered to be part of central Europe.
} 
Aesthetic culture. In 1997, Ferrell explained that the definition of deviance may result from social conflicting views on the notion of "cultural space", which identifies the ways in which different societal groups interpret the use of public spaces and shape their presence within them. Powerful majorities often take the lead in defining what is considered an appropriate behaviour and an agreeable aesthetics in public spaces, and coercively impose their values on marginalised populations. A number of studies have been conducted by cultural criminologists to investigate the construction of urban subcultures as deviant and the processes of criminalisation applied to them (Ferrell, 1995a, 1995b; Ferrell and Sanders, 1995; Lyng and Bracey, 1995; Hayward and Yar, 2006 etc.), also with respect to street drinkers (Jayne et al., 2006; Galloway et al., 2007).

As postmodern consumers, street drinkers may have a specific taste in clothing or outer appearance and adopt a certain specific aesthetic style (Featherstone, 2007).$^{13}$ Their aesthetic appearance may in turn have an impact on law enforcement agents' representation of and response to the nuisance in which street drinkers participate. Such an effect may, however, vary in uneven socio-cultural contexts: enforcement practices may be influenced by specific aesthetic expectations and preferences, which may very much depend on the specific socio-cultural context in which they are embedded (Jordan, 2000; Masuda et al., 2008; Millie, 2008).

In Italy, exclusive policies and (penal or administrative) practices directed to categories of people who are considered as "aesthetically different" (e.g., immigrants, homeless, Roma, prostitutes etc.) have been described and analysed along the years by a number of scholars (Melossi, 2000; Quassoli, 2004, 2013; Parmigiani, 2008; Carbonaro and Quassoli, 2013; Colombo, 2013; Di Ronco, 2014 etc.), which may suggest that personal or group style is considered a particularly important factor when addressing certain groups in Italy.

In Belgium, by contrast, aesthetic appearances of individuals and groups may have a more reduced impact on penal actors. Although Belgian scholars have attributed a role to factors like ethnicity and conditions of social and economic deprivation in determining the perceptions, decisions and practices of penal actors, these factors have been found to have an impact only when occurring in conjunction (Snacken et al., 1999; Snacken, 2007) or in combination with other elements (Easton and Ponsaers, 2010). ${ }^{14}$

\footnotetext{
${ }^{13}$ Feathersone (2007) highlighted the importance of style in postmodern society and the existence of (postmodern) consumer lifestyles in urban city centres, which are based on the acquisition and display of consumer products and on the individual engagement in hedonistic and playful activities. Despite recognising the existence of different lifestyle tastes within social groups or classes, Featherstone (by referring to the work of Bourdieu) argued that specific social classes (and, especially, the "new" middle classes) tend to impose their specific tastes as the "legitimate" ones.

${ }^{14}$ Easton and Ponsaers (2010), for example, found that police representation of and reactions to problematic populations in multicultural neighbourhoods is based on ethnicity and immigration as much as on an array of other factors (e.g., age, gender, situation of marginality, poor socio-economic and cultural capital etc.).
} 
Drawing on this theoretical background, it is hypothesised that physical appearance or style of street drinkers, especially when clashing with the aesthetics of police officers as "aesthetics of authority" (Ferrell, 1995b), plays a more powerful role in shaping police officers' views on the nuisance of public drunkenness and their enforcement practices in Trento than in Ghent.

\section{City selection criteria and methods of data collection}

The present research focuses on two cities: Ghent, situated in the Flemish Region of Belgium, and Trento, located in the northeast part of Italy. ${ }^{15}$ The decision to focus on the study of cities rather than of countries has been taken in view to allow city-specific cultural factors to emerge. In a country, different and multiple cultures may be present, thus potentially leading to different visions of and approaches to drinking and public drunkenness (Anderson and Baumberg, 2006). Also within cities, however, different drinking cultures may arise from the drinking practices of specific socio-economic groups attending uneven nightlife locations. Notwithstanding the presence of a variety of youth (sub)cultures showing different drinking habits, studies have found that in many cities in the UK the "mainstream" (Hollands, 2002: 153) type of identity and its consumption patterns tend to dominate the nightlife scene (see also Chatterton and Hollands, 2002), in this way suggesting that drinking patterns within a city (and its nightlife locations) may not vary that much.

Ghent and Trento have been selected for them presenting a number of similar characteristics. For example, they are not capital cities but provincial centres highly populated by students. Many colleges' and universities' campuses are present in Ghent (Universiteit Gent, Gent Hogeschool and Arteveldehogeschool) and in Trento (Universitá degli Studi di Trento). In both of them, moreover, local policy-makers have enacted a regulatory framework that punishes both individuals ${ }^{16}$ and licensing premises ${ }^{17}$ for a variety of uncivil behaviour connected to public drunkenness.

\footnotetext{
${ }^{15}$ One of the two hypotheses that are to be tested in this paper refers to the specific cultural differences that exist between Western European countries and the southern countries of the region. Any pair of cities situated in these two areas would have served the purpose of the exercise. Ghent and Trento have been selected also based on the author's previous (in Trento) and current (in Ghent) living experience in these two cities.

${ }^{16}$ In Ghent, a number of individual uncivil behaviour that may be also connected to public drunkenness has been penalised by way of administrative fines by the Police Regulation on Public Peace and Safety of 19 January 1998. In Trento, they are sanctioned by art. 85 of the Urban Policing Regulation.

${ }^{17}$ Administrative fines have also been envisaged by local regulations to sanction bars and clubs' owners. In Ghent, to limit and control the noise nuisance emanating from liquor licensed premises a new regulation (Vlarem) has recently entered into force (see http://www.gent.be/eCache/THE/4/216.cmVjPTE0NzYzMg.html). Also the opening of new night shops and the selling of alcoholic beverages by them has been limited by way of local regulations (see local regulation of 26 June 2012). In Trento, bars of the city centre need to comply with
} 
Semi-structured interviews have been carried out with local police officers patrolling the areas that are mostly concerned with alcohol-related disorder. Interviews have been held with the Lokale Politie, in Ghent, and the Polizia Locale, in Trento, which are competent to apply both contraventions for public drunkenness and administrative fines for the nuisance behaviour connected with it.

Interviewees have been selected according to purposive or purposeful sampling (Dantzker and Hunter, 2006), which allowed for the selection of the police officers based on their competences and powers to enforce regulations on public drunkenness. Interviews have been held with 8 police officers, in Ghent, and with 9 agents, in Trento. The interviews have been semi-structured and involved the use of a checklist, containing the list of main themes and topics to be discussed with the interviewees. Police officers have been interviewed until the level of saturation was reached, that is, when the information that was gathered did no longer add value to the data already collected (McLaughlin and Muncie, 2005). Interviews have been transcribed, coded and anonymised.

To explore the nuisance of public drunkenness, the research has relied on systematic observations (Mastrofski et al., 2010), which are based on the observation of social phenomena and activities occurring in their natural settings according to specific rules that permit replication (Reiss, 1971). Observations took place, in Ghent, during the last week of August (from 22 to 28 August 2014) and, in Trento, during the first week of September (from 2 to 8 September 2014). ${ }^{18}$ Observations have been carried out from 22.00 to $1.00{ }^{19}$ consecutively during seven evenings in selected spaces of the city centre that are well-known for their vivid nightlife. Such sites have been identified by police agents during the interviews and have been described by them as hot spots for the nuisance behaviour connected with public drunkenness. Those spaces are, in Ghent, the area of the Vlasmarkt, and, in Trento, the zone encircled within Santa Maria Maggiore Square (henceforth: SMMS). In Ghent, to

rigid limits in the levels of noise emissions (see the Acoustic classification plan available at http://www.comune.trento.it/Aree-tematiche/Ambiente-e-territorio/Rumore-e-elettromagnetismo/Rumoreambientale/Classificazione-acustica).

${ }^{18}$ In such a period of time, the presence of college students in both cities is rather limited due to the academic summer break. In this study, however, the presence of students has only accounted as a criterion for the city selection, not as an element informing the decision on the period of the observations. Rather than focusing solely on the drunken behaviour of students and young people, this research includes the analysis of the drinking habits and disorderly conduct of any person present in the selected location.

19 In some cases, the ending-point has been extended or postponed according to specific situational circumstances emerging during the observations. During weekends, for example, the time-span of the observations has been prolonged due to the large presence of people in both selected areas. In one occasion (on Saturday evening in Ghent), the starting point of the observations has also been postponed. This has been done on advice of a number of bartenders working in the cafes of the Vlasmarkt, who associated the occurrence of nuisance behaviour with the late hours of the night. The observations, therefore, have started at midnight and have been carried on until 5.00. This, to allow the researcher to grasp the nuisance behaviours happening late in the night. 
inspect the nuisance behaviour of drunken people in the late hours of the weekend's nights, observations have been carried out also in the close-by area of the Oude Beestenmarkt, which is crammed with clubs and bars open until 5.00-6.00. Also in Trento the spaces of observations have shifted from SMMS and via San Giovanni to via Roma, via delle Orfane and vicolo Colico after midnight. Increasingly after 23.00, people left the area of SMMS and moved to the bars of the surrounding streets. The area was left deserted at midnight, when the bar and the night shop situated in via San Giovanni shut. ${ }^{20}$

Drawing on the coding instrument developed by Weisburd and colleagues (2012), observations have been carried out through the utilisation of a coding sheet, which has been compiled with written field notes and with other techniques for collecting data (e.g., taping, recording and photographing). Through field notes, both the observed elements and the researcher's experiences have been noted down (Hale et al., 2005; Nelken, 2012). Elements that have been observed included: (1) the number of people present in the area per time-span; (2) the average age/gender of people; (3) the amount of alcohol purchased per capita; (4) the level of intoxication; (5) the presence and/or interventions of law enforcement agents and of place managers; and (6) the number of violent and disorderly behaviour. Nuisance behaviour of drunken people has been measured by taking into consideration the action of people: (a) littering; (b) urinating; (c) causing loud noise; (d) yelling; (e) loudly disputing; (f) physically assaulting others; and (g) engaging in vandalism (including graffiti and tags).

To check whether there are similarities or differences in the representation of, and enforcement against, the nuisance of public drunkenness in the two selected cities, the gathered empirical data have comparatively been analysed.

\section{Results}

\section{Observations}

Ghent. From the observations in Ghent, it emerged that the drinking modes and practices of people very much varied in the weekend and during week days. In early hours of Friday's and Saturday's evenings, drinking mostly occurred inside bars and involved the consumption of both beer and spirits, for men, and of cocktails, wine and non-alcoholic beverages, for women. In Belgium, beer may have a different alcoholic concentration (ranging from $3 \%$ in standard beer to $9,5-10 \%$ in strong beer or Trappist) and is rather cheap, as its price

\footnotetext{
${ }^{20}$ Also in the areas surrounding SMMS, bars normally close not later than 2.00-2.30. This has probably to do with the municipal regulation on noise emissions with which bars and clubs located in the city centre need to comply.
} 
stretches from 2 to approx.. 4 EUR. According to the bartenders of the clubs of the Vlasmarkt (where bars normally shut at around $2.00-3.00)^{21}$, during weekends people are used to drinking approximately 7 to 8 drinks each and to mostly consume all types of beer, as well as cocktails made from rum and gin. The age range of people found there was also very wide: they were both youngsters (around 18-year-old) and older people (up to 40-50 years old).

After midnight the number of people in the Vlasmarkt started to decrease, whereas it increased outside the bars of the Oude Beestenmarkt (to up to 130 people). Here, men and women (whose age range stretched from 25 to 30 years old) were to be found both outside and inside bars, predominantly consuming standard beer. The bartenders indicated that the level of alcohol consumption in the Oude Beestenmarkt is rather high during the weekend: both men and women drink from 15 to 20 standard beers per night, or an elevated number of strong beer and of cocktails made from gin, rum and whiskey.

In the weekend, nuisance behaviour connected with public drinking and drunkenness mainly occurred after midnight and was observed until earlier hours of the morning, with prevalence during the time-span from 1.00 to 3.30-4.00. On Friday evening, cases of verbal disorder (4), littering (5), urinating (3), public drunkenness (4), loud noise or music (6) were observed. Also an episode of physical aggression was noticed. The incident involved two young men, who were first verbally disputing, and then physically fighting approx. 20 meters from the bars of the Oude Beestenmarkt. The fight was quickly brought to an end by one of the two quarrellers, who managed to run away. Not only there was no requested ${ }^{22}$ police intervention to deal with the fight, but police presence in the area on Friday was also limited to four police cars occasionally passing by the main road and heading either to the city centre or to the police station situated close by.

On Saturday, a higher frequency of nuisance behaviour was recorded. In the selected night life location, people were yelling (16), littering (19) and urinating (7) next to the bars' front doors (in the Vlasmarkt) and next to the river bank (in the Oude Beestenmarkt). The level of intoxication of people was also quite high in comparison with the other days, as I observed 12 cases of people vomiting, swaying, and falling down. Cases of loud noise and music were also noted down (11), as well as the presence of five police car passing by. No reactions were noticed on the part of the residents, or of the people passing by the observed area, who did not pay much attention to the behaviour of drunks and to the presence of people drinking outside bars.

\footnotetext{
${ }^{21}$ With the exception of the Charlaton, which shuts at around 6.00-7.00. Such a club, however, was closed up for holidays during all the 7-nights of observations.

${ }^{22}$ As the bartenders pointed out to the researcher, nobody from the bars called the police to report this episode of violence, nor did they receive any complaint from the costumers. It was then assumed that nobody called the police.
} 
During weekdays, the drinking habits and behaviour of people in the selected area were rather varied. On Sunday, Monday and Tuesday evenings, for example, little to no people were observed outside bars both in the Vlasmarkt and in the Oude Beestenmarkt, and only a few of them were sitting inside cafes. This, at least partly, may be connected with the bad weather conditions of the aforesaid days, which included heavy showers, moist and low temperatures. According to a number of bartenders, a lower or limited presence of people during weekdays in the cafes of the area is a quite usual circumstance and quite normal in that period of the year.

On Wednesday and Thursday, by contrast, a higher amount of people was observed in the selected nigh-life location, mostly consuming beer in the external terraces of bars. An exception was represented by a group of approximately 20 young people (around 18 to 20-year-old), who were standing or sitting in a small parking lot in the middle of the Vlasmarkt on Thursday evening. This group reached the spot at around 23.00, already inebriated from the consumption of alcohol and quite euphoric. After drinking the beer that they had with them, I observed them buying new cans from the frituur (a typical fast food) present in the area, which sells very cheap drinks. Overall on Thursday evening, there were 11 episodes of littering, 4 of loud noise or music, 28 of verbal disorder and one case of a person urinating. There were also a loud dispute and nine cases of drunkenness.

Trento. In Trento the patterns of drinking did not substantially vary from the weekend to the weekdays. In almost all days of the observations, the presence of people in SMMS was conspicuous and higher in earlier hours of the evening (from 70 to almost 200 people), whereas it started to decline around 23.00-23.30, when the observations were moved to the close-by via delle Orfane and vicolo Colico (where the number of people ranged from 60 to 100). Only on Sunday evening there was barely anyone in the observed area. During all the other days when the observations were carried out, young people (from approximately 18 to 23 years old) ${ }^{23}$ were spotted sitting in a little square and drinking predominantly beer, which in Italy has a low alcohol concentration (2.5\%). Mostly, they were cans or bottles bought in the night shop in via San Giovanni, which sells very cheap beer (1 EUR). In some instances, I also observed people taking beer from bags showing the logo of popular

${ }^{23}$ The great majority of people present in SMMS during the observations were Italian college students. However, there were also people from the north of Africa (mostly refugees), and a small number of (middleaged) homeless (5), all drinking beer in cans or bottles. According to a north African man, who was informally interviewed during the observations, there are differences between the drinking patterns of people from the north-African region and the ones of Italians present in the night-time area: in opposition to young Italians (who tend to behave uncivilly by mostly leaving litter in the area, urinating and yelling), people from the countries of the north of Africa, when drunk, tend to engage in fights and violent behavior, as they are not used to drinking alcohol in their home countries due to religious prohibitions. An indication of the violent behavior adopted by this latter group of people when intoxicated by alcohol can be found below in the text, where I describe the physical attack that was carried out by a young north African man against one Italian during the Saturday evening in SMMS. 
supermarkets. Only a limited number of people were drinking beer and aperol spritz ${ }^{24}$ purchased in the bar, where drinks are more expensive (beer cost 2 EUR, whereas aperol sprits cost 2.50 EUR) and are served in plastic glasses. According to the owner of the bar situated in SMMS, people only order 2 to 3 drinks at the bar's counter and prefer to purchase cheaper drinks in the close-by night-shop or to bring them from home. Among the drinks that are mostly consumed by people at the bar, there is beer, aperol spritz and spirits, which are often ordered by youngsters (18 to 20 -year-old) "who want to get drunk very quickly". The age profile and drinking habits of people changed when the observations were moved to via delle Orfane and vicolo Colico, where individuals were aged around 25 to 30 -year-old and were ordering beer, wine, cocktails and spirits at the bars (both women and men).

Not only people in Trento started to drink early in the evening, they also adopted disorderly behaviour quite early in time. Episodes of people yelling, littering, and urinating were observed since 22.00 during six of the seven evenings. Generally speaking, cases of nuisance were quite recurrent in the selected nightlife location. On Tuesday, for example, 39 cases of littering were noticed, alongside 6 episodes of loud noise or music and 29 of verbal disorder. On Saturday, 9 cases of people littering were recorded, along with 6 episodes of loud noise, 12 of verbal disorder and one loud dispute. In 11 cases, people were observed urinating in the small alley of SMMS. There were also a high number of drunken people, who were swaying or sleeping on the ground (9).

On Saturday in front of the bar in via San Giovanni, a verbal dispute between two young man, one Italian and one from the north of Africa (Tunisia), resulted in a physical aggression carried out by the latter (who, according to the witnesses, was drunk). Shortly after the fight, an ambulance got to the area to help the injured man, together with four agents of the Polizia di Stato, who questioned the witnesses about the fight and the assailant (who immediately left after the attack). Later the same night, I also observed two officers of the Polizia di Stato dealing with two cases of public drunkenness in via Roma. The intervention of the police was requested by the costumers of a bar, who were bothered by the conduct of two drunks who were yelling and starting to become aggressive. With the support of the bar owner, the two police officers encouraged the drunks to leave the place and applied no sanction to them. The same evening, I noticed a resident walking through the area and being visibly disappointed with, and frowning at, a few people dealing drugs. The person seemed to pay conversely less attention to the presence of young people drinking there. More confrontational was the attitude of two other persons on Monday, who checked the conditions of the area and engaged with a few intoxicated people, asking questions about the frequency of their presence in the area, the quantity and type of substances used etc. They

\footnotetext{
${ }^{24}$ This is a typical aperitif of the north-east area of Italy, made from aperol, Prosecco and soda.
} 
were the police superintendent and one assistant in their civilian clothes, wanting to have a check on the issues of the area after the case of violence happened on Saturday. ${ }^{25}$

\section{Semi-structured interviews}

Ghent. The Ghent police officers described the nuisance of public drunkenness as any behaviour of drunken people which irritates others and associated it with loud noises, vandalism, violence and sometimes also with litter. Except in one case, it has not been linked up with the mere presence of a drunken person sleeping in a public space (on benches, on the sidewalk etc.). The definition of nuisance (in Dutch, overlast) has also coincided with the legal definition of public drunkenness ${ }^{26}$ or with that of public disorder ${ }^{27}$, which are two contraventions punished with administrative fines. According to police officers, the first category (public drunkenness) includes the case of a drunk and disorderly person who is annoying other people, as well as the case of a person who, without bothering anyone, is excessively intoxicated from alcohol and may be a danger to her- or himself or to others. The second category (public disorder) encompasses cases of drunken people who are violent and aggressive. In both cases, the drunk is fined administratively and detained up to 12 hours at the police station. Measures against public drunkenness and public disorder are applied by police agents only when strictly necessary and after having pursued a sort of mediation with the drunk person (what they called the "middenweg" (transl.: midway) approach).

Despite the given definition of nuisance, police officers said to only rarely apply administrative fines targeting incivilities of drunken people. Public drinking and drunkenness have been understood to be two very common phenomena in the locality, especially when associated with the presence of young people and students, which are

\footnotetext{
${ }^{25}$ The presence of the police chief was pointed out to the researcher in an informal conversation with a person who deals drugs in the area, who emphasized that his presence there is not an unusual circumstance. Quite the opposite, the police chief is often seen in the area after the occurrence of grave episodes of physical aggression (like the one occurred on Saturday). This, as pointed out by frequent visitors of the area in informal conversations, has to be reconnected with the raising complaints of the residents, which challenge the action of the local law enforcement also through the local press. Although I did not seek for a direct contact with the police superintendent, I had informal conversations with his interlocutors.

${ }^{26}$ Public drunkenness is sanctioned by the Belgian Law of 14 November 1939, where it is stipulated that: "The person who is found in a state of intoxication in a public place is punished: [...] with a fine of 15 francs [0.40 EUR] to 25 francs [0.60 EUR] [...] if the offender causes disorder, scandal, or danger to another person or to himself, he can be detained in the municipal house of detention or in the security room of the gendarmerie for a minimum of two up to a maximum of twelve hours".

${ }^{27}$ Public disorder is an offence envisaged by art. 31 par. 2 of the Law on Police Services of 5 August 1992, which allows police officers, "in cases of absolute necessity", to arrest "a person who disturbs the public peace".
} 
a segment of the population who since long has been involved in the nightlife scene of the area. According to two respondents, interventions against the nuisance of public drunkenness are carried out as long as they are strictly necessary. Otherwise, as they said, "you would have all the student population in jail”, or "there will be the prison full of students ...every night 50 students down here ... and that is not workable".

To explain this lenient police enforcement, respondents made reference to the (socially recognised) role that the activity of drinking plays in the local culture. As some of them pointed out, in Ghent there is "quite a culture of bars and cafes", in the meaning that the consumption of alcoholic drinks mostly occurs at the bar and only rarely at home, for instance, during meals. Respondents also regarded the activity of drinking with friends (at the bar) and with family members (at family parties and celebrations) as a very common and widespread habit. As suggested by a few of them, although drinking in public spaces may not be accepted by every member of society, it is overall tolerated. What is socially not tolerated is the behaviour of people who "cross the line" and bother or threaten others. As one of the interviewees explained: "there is no problem in being drunk, not even in drinking during the day, as long as the rules are respected: people cannot run across the streets, ignore red lights, they should walk properly .. In short, they need to act normal".

According to the Ghent police officers, also residents living in the Vlasmarkt and in the Oude Beestenmarkt are rather tolerant when it comes to addressing the nuisance behaviour of people drinking and drunk: they rarely call the police to complain about episodes of disorder happening in the area. As police agents put it, "they knew it before" (that the area was one of the city hot-spots for parties) and they need to have a "ticker skin". As three interviewees added, a factor that may explain the high tolerance of residents towards drunkenness and alcoholrelated disorder may also be related to the low level of police reaction to such cases. Since public drunkenness does not constitute a priority for the local policing strategy, "residents know that they may wait also quite some time before any action is taken by the police" in response to their complaints.

Trento. The Trento police officers imputed the nuisance and disorderly behaviour of people drinking and drunk to the presence in the selected nightlife location of three groups of people: firstly, of students and young people drinking during happy hours; secondly, of punks, members of the anti-globalization and anarchic movements drinking in squares and in other public spaces; and, thirdly, of groups of "foreigners" or of "illegal immigrants" drinking and getting rowdy. 
When talking about young people and students, three respondents pointed out that drinking in the city and, more generally, in the region (Trentino) is very much widespread and has a prominent social (and commercial) ${ }^{28}$ role. In the words of one police officer: "the average-person in Trentino drinks a lot. People here drink at home during meals, at the bar with friends and also at public celebrations and manifestations. During happy hours students drink. But here they drink at all ages. During public manifestations, for example, you can see 15 or 16 year-old people drinking alcohol, as well as people who are 70". As this fragment points out, drinking alcohol, also when pursued by young people, is socially accepted. What is not tolerated (and has been defined as nuisance by police officers) is the presence in the selected nightlife location of large groups of young people at night, which has often been associated with certain types of uncivil behaviour (e.g., yelling, littering and urinating).

Nuisance behaviour has also been linked to the presence in the area of punks, members of anti-globalization and of anarchic movements, who are said to have a specific dressing style and lifestyle. As one of the police officers clarified, "you can spot them from the way they are dressed... they are the rebellious, those from the anarchic centres, who do not have a job... they are many! [...] The leaders (if we may call them like that but anyway there is a hierarchical structure) who organise the rallies etc. are the sons of politicians, entrepreneurs... they are those who when get tired of playing the rebellious have their backs covered... and then leave behind a trail of others who are left empty-handed (they don't go to school etc.)... they protest because they know that even if they make a mess they are left unpunished". According to another police officer, punks and members of anarchic movements "create confusion" and "degrade" with their presence "the beauty of the historical monuments located in the area".

Alcohol-related disorder has also been attributed by police officers to "foreigners" coming from the eastern parts of Europe, where people are normally "very much used to drinking". As one of the respondents clarified, you "recognise" the people who create disorder "from their different nationality [...] I speak about certain nationalities because - I don't want to be racist - some, like the ones from east Europe, have the habit to drink all since very young... By them that is the norm". A representation of this group of people based on the outer appearance of its members was offered by respondent N. 7, who described disorderly immigrants in the following terms: "they participated in the war... you can spot them from the attitudes they have, from their large, broad and strong build... they are mostly from eastern Europe and former-Yugoslavia [...] but they can also have other nationalities". Police officers attributed disorder also to "illegal" immigrants coming from the countries of

\footnotetext{
${ }^{28}$ A few interviewees also made reference to the importance of alcohol for the local economy. One of the interviewees, for example, referred to the strong influence exerted by the "powerful lobby of bar keepers" in the local policy-making.
} 
the north of Africa, where drinking is said not to be allowed due to religious dictates. The effects of excessive drinking are viewed similarly for both groups, as they are said to likely engage in fights.

An exception in the representation of the nuisance of public drunkenness was made by the second and the third interviewees, who associated it with the presence of drunken homeless sleeping on benches or on the sidewalk. For the other respondents, by contrast, the presence of a drunken homeless (despite creating "discomfort", as one of the respondents clarified) is socially tolerated and does not account as disorder. According to respondent N. 3, moreover, disorder had a strong connection with the outer/aesthetic characteristic of a certain group of people: only drunken individuals who are "shabbily dressed" are said to create nuisance.

The Trento police officers have mostly associated their responsive interventions with cases of violent and aggressive behaviour of drunken people. ${ }^{29}$ However, especially when drunken "foreigners" engage in fights, police intervention is said to be rather difficult to pursue due to the speed of such accidents. When police officers reach the spot (normally, within 5-6 minutes), the fight is often already over and they do not manage to identify the people who were involved in it.

Sanctioning uncivil behaviour of drunk young people has also been viewed as a difficult task to accomplish, especially when incivilities happen not in isolation but inside (or close to) a large group of individuals. In such cases, police intervention is hindered by concerns about the operators' personal security, which may be jeopardised by retaliations and acts of violence pursued against them. Such a limited policing capacity has also been linked with the reduced number of agents of the Polizia Locale working during the night shift (only two).

Also illegal immigrants adopting uncivil behaviour (e.g., littering, urinating, yelling etc.) are seldom sanctioned by police officers. Again, the explanation of such a policing attitude has been connected by police officers with (mere) pragmatic considerations. As respondents clarified, such a category of people "almost never" pays the fine. Imposing a sanction on them is, therefore, considered as "useless" and "time-consuming".

Despite these practical concerns and difficulties, a police intervention is said to always quickly follow a complaint of public drunkenness or of disorderly behaviour. Especially when the call comes from the residents of the area, police agents strive to "do something" about the problem being complained about. For example, uncivil behaviour is sometimes sanctioned indirectly by the police, that is, by way of an administrative fine imposed to the bar around which incivilities occur. When uncivil behaviour does not happen in connection with a bar, police action is limited to patrolling and monitoring the area where disorderly behaviours are adopted.

\footnotetext{
${ }^{29}$ Here, the contravention envisaged at art. 688 of the Italian Criminal Code applies: "Anyone who is caught in a state of obvious intoxication in a public place [...] shall be punished with the administrative fine from 50 to 309 EUR".
} 
This, mainly, to avoid (or to reduce) residents' negative reaction to and dissatisfaction with police action, which is also very much reflected in the media.

Societal tolerance in SMMS is viewed by police officers as being rather low. The residents of the area have been described as being particularly hostile against young people consuming alcohol during happy hours, especially with respect to the noise and to the practice of urinating against the front doors of the buildings. As they put it, residents call “very often”, “always", “also for no reason”, “even in anticipation”, and "anyway too much”. The intolerance of residents and, more generally, of citizens is seen as a product of long standing media campaigns, which have succeeded to amplify societal and individual concerns about the level of (physical and social) disorder in the area (or to create a "collective phobia", as one of the interviewees suggested), and to enhance their perception of insecurity. Police agents explained citizens' conservative mentality through diverse factors. Among others, there is the quick expansion of the university, which only in recent years has led to a significant growth in the number of students and, therefore, to the introduction of specific entertainment opportunities for them. Happy hours, for example, have only recently been introduced in the city, causing intense community protests and initiatives aimed to counter the blight of the area. ${ }^{30}$

\section{Discussion}

From the review of the data gathered through the systematic observations, it emerges that the hypothesised different culture of drinking only partly explains the drinking patterns and behaviours of people in Ghent and in Trento.

Drawing on the "wet-dry" dichotomy (Room and Mäkelä, 2000), it was firstly hypothesised that drinking in Ghent was infrequent and that it occurred during a long(er) span of time, whereas in Trento it was regular and happened in the early hours of the evening. This first part of the hypothesis was confirmed during the observations. In Ghent, a very limited presence of people was observed in the selected area on Sunday, Monday and Tuesday, both outside and inside bars. During weekend, when the presence of people was more substantial, individuals were observed drinking alcohol until very late (also due to the longer opening hours of clubs and bars). In contrast, drinking started early in the evening in Trento, where a consistent number of people was observed consuming alcohol during 6 of the 7 days. A lower frequency in the consumption of alcoholic drinks in Ghent has also been confirmed by the interviewed police officers, who have mostly associated the consumption of alcohol with (semi-)public venues like bars and cafes, rather than with private places and homes.

\footnotetext{
${ }^{30}$ See Comitato Torre Vanga https://www.facebook.com/groups/236481156509302/?fref=ts.
} 
Secondly, it was hypothesised that people in Ghent mostly drank beer, while in Trento they consumed wine in moderate amounts. This second segment of the hypothesis was not confirmed through the observations. Generally speaking, in both cities beer seemed to be the most popular drink consumed by alcohol users. The type of alcoholic beverage drank by people in Ghent and Trento, however, varied according to the time-span, the street segment, the age and the gender of alcohol users. Before midnight in the Vlasmarkt, for example, both young and older people consumed a wide variety of drinks: while men were observed drinking beer and spirits, women drank wine, cocktails and non-alcoholic drinks. After midnight in the Oude Beestenmarkt, 25 to 30 -yearold people drank standard beer. In Trento, youngsters (from 18 to 23 years old) in SMMS predominantly consumed beer and, only the bar's customers, aperol spritz. After midnight in vicolo Colico, 25 to 30 -year-old people were observed drinking beer, as well as wine, cocktails and spirits. Informal conversations with bartenders also underscored the popularity of cocktails made from gin, rum and whiskey, in Ghent, and of spirits among youngsters, in Trento.

Thirdly, it was expected that the quantity of alcohol consumed per capita was higher in Ghent than in Trento. In contrast to the expectations, the number of drunken people did not significantly vary in these two cities: while in Ghent there were 26, there were 22 in Trento. Also the information gathered in informal conversations with bartenders (who attributed higher alcohol consumption to the people in Ghent) does not help in this respect. Bartenders in Trento have clarified that their information about individual alcohol consumption is very limited, as people there tend to purchase cheap drinks in supermarkets or in night-shops (rather than in bars). It is therefore difficult to establish the precise amount of drinks purchased and consumed by people in Trento every evening.

Lastly, it was assumed that disorderly and violent behaviours were more prevalent in Ghent than in Trento, due to a higher level of alcoholic intoxication reached by people in the former city. This third part of the hypothesis found no support in the data gathered during the field work, which indicates that the level of disorderly behaviour does not vary that much in these two cities. While in Trento 85 episodes of littering were noted down, alongside 87 cases of verbal disorder, 4 of loud dispute and 16 cases of people urinating; there were 36 (littering), 63 (verbal disorder), 2 (loud dispute) and 11 (urinating) in Ghent. In both cities, one case of physical aggression was observed. Also the cases of loud noise and music did not substantially differ in Ghent (36) and in Trento (27).

In short, if the difference between the "wet" and the "dry" cultures contributes to explaining the uneven time/duration of alcohol use in Ghent and Trento, it does not explain the similar type of beverage selection 
(beer), as well as the similar level of intoxication and of disorderly behaviour. As such, the results seem to align with the studies that argue for a homogenization in the drinking patterns of Europeans (Room and Mäkelä, 2000; Anderson and Baumberg, 2006; Mäkelä et al., 2006; Gordon et al., 2012). A high level of alcohol consumption and of nuisance behaviour in the nightlife location of the Italian city of Trento may be explained in light of the recent change that occurred in the drinking habits of people attending the area. An indication of this recent change can be found in the perceived negative societal attitudes that residents have towards public drinking and drunkenness in the concerned nightlife location (as opposed to the perceived tolerance of the dwellers of the selected night-time area of Ghent). As police officers suggested during the interviews, the recent expansion of the university has led to a rise in the number of college students and to the organisation of entertainment opportunities for them. The increased consumption of alcohol, however, does not only happen in combination with happy hours. As the observations showed, from early hours of the evening until late in the night people in SMMS were sitting among groups of friends and drinking cheap drinks. In a few cases, also very high states of intoxication were reached by people, in this way resembling the phenomenon of "el botellón" widespread among Spanish youngsters (Gual, 2006; Järvinen and Room, 2007).

From the review of the results of the interviews with police officers in Ghent and Trento, a different representation of the nuisance of public drunkenness has emerged. In Trento, police agents associated alcoholrelated disorder with the presence in the selected nightlife location of specific groups of people, who are students, punks and members of anarchic movements, immigrants and homeless. Furthermore, three police officers pointed at the specific outer/aesthetic characteristics of punks, immigrants and homeless. By contrast, a more normative approach has been evidenced in Ghent, where nuisance behaviour connected with public drinking and drunkenness coincided with the conduct of drunken people who bother others and/or with situations where the intoxicated person constitutes a danger to him- or herself or to others, that is, with any behaviour that is considered to move away from the "normal", or the socially accepted, standard of drinking.

The fact that only in Trento police representation of nuisance has referred to the description of the outer appearances and looks of specific groups may provide an indication of the role that aesthetic or physical characteristics may play in shaping police representations of and attitudes to nuisance there. However, since a clear reference to the aesthetic characteristics of certain groups of people was only made by 3 of the 9 agents interviewed (which may not be representative of the sample of police officers in Trento, not even of the Polizia Locale), such a reference may also be explained through other elements. For example, the responses of the agents mentioning aesthetics as a factor may have been influenced by their personal biases and stereotypes 
towards particular groups of people, by their capacity to speak with property, or to use the language in a correct way. Police officers may also have given answers that were affected by the social desirability bias, that is, by an attitude to give answers that are thought to be viewed positively by other people.

In spite of a different representation of the nuisance of public drunkenness, police officers in Ghent and in Trento apply a similar (and low) level of enforcement of national and local regulations on public drunkenness and related nuisance behaviour. They do so, however, in light of different arguments. As the Trento police agents pointed out, they rarely proactively sanction students, punks, members of the anti-globalisation movement and anarchic people drinking and getting drunk in public places. This, in light of mere pragmatic reasons: the reduced number of police officers at nights prevents them from effectively addressing and sanctioning a great number of drunk and disorderly people, lest being targeted of aggressions and violence.

The same set of arguments was employed by respondents to describe their enforcement attitudes to the disorderly behaviour adopted by "foreigners" getting drunk and rowdy. In these cases, sanctions are not applied by the Trento police officers due to their often late intervention (in case of fights) or to the perceived absence of any deterring effect carried by the sanction (in case they adopt other types of uncivil behaviour). ${ }^{31}$ In other words, sanctions are not applied by police officers because it is difficult or useless to do so, rather than because of a permissive policing attitude to public drunkenness and related disorderly conduct. Some evidence of such a police trend may be found in the official statistics of the Polizia Locale, which since 2010 have registered only 18 cases of public drunkenness in the city centre. ${ }^{32}$

Despite the reduced number of sanctions, the Trento police agents seem to consider public drinking and drunkenness and, above all, the nuisance behaviours that are connected with it, as a priority of intervention. They have explained this attitude in light of the perceived high social intolerance of residents (and their committee) and of the elevated media coverage of the episodes of disorder that happened in the area. As police officers put it, a reactive intervention always quickly follows a complaint of the residents and may result into a sanction issued to the bars, which are deemed to be responsible for the uncivil behaviour of their clients. When nuisance does not happen in connection with a bar, police intervention is limited to patrolling the area and to monitoring the situation.

\footnotetext{
${ }^{31}$ The two cases of public drunkenness observed on Saturday evening have not been considered in this part of analysis, as the intervention was pursued by agents of the Polizia di Stato, rather than by the Polizia Locale (on which this paper is focused).

${ }^{32}$ Local police statistics rely on aggregated data, which refer to the time-span stretching from January 2010 to October 2014.
} 
Context-specific cultural factors such as the recent increase in the number of college students and the introduction of happy hours may help to explain such a (perceived) negative attitude of residents to the nuisance of public drunkenness in Trento. As police officers suggested, new drinking patterns of students in the night-life location may have opposed to the traditionally recognised and tolerated practices and sparked residents' (and citizens') intolerance. Although the observations did not directly show any such a negative attitude on the part of residents, they did so indirectly and, notably, through the observed presence of the police superintendent in the selected zone. Such a presence was regarded by a few frequent visitors of the area as a response to the pressures exercised upon law enforcement agencies and the municipality by both the residents and the local press. ${ }^{33}$

Also the Ghent police officers rarely sanction public drunkenness and connected nuisance behaviour. ${ }^{34}$ Different (and, mostly, normative) arguments have, however, been provided by them to justify such a similar policing strategy: police intervention is carried out only when strictly necessary and, mostly, for cases of public drunkenness and of public disorder. Such cases, however, are not considered to be a priority in the local policing strategy. Interventions of police agents have been described as being predominantly reactive and, thus, to follow a phone call of annoyed costumers. Police presence in the area is, in fact, only eventual and connected with its particular location within the city (which is situated halfway between the closer police station and the city centre). The Ghent police officers connected the permissive law enforcement approach to public drunkenness and related nuisance behaviour with the high frequency of cases of drunkenness registered in the area and, more generally, in the city. According to the local police statistics, the number of accidents of public drunkenness in Ghent has been quite steady in the past two years and five months: they were 329 in 2012, 298 in 2013 and 112 until May 2014 (in line with the cases reported until May of the previous two years). In the Vlasmarkt, 54 accidents of public drunkenness have been reported in this time span, whereas they were only 4 in the Oude Beestenmarkt.

Police officers linked such a permissive law enforcement approach also with the high level of tolerance of citizens and residents towards the activity of drinking and, to a certain extent, also towards the state of public drunkenness. Such a tolerant societal attitude has been explained through the socially recognised role that drinking (both in bars and in public spaces) has in the local culture and, by a few of them, also through citizens' awareness of the late and eventual police reaction to cases of public drunkenness. A neutral (if not positive)

33 For a media news published in the last day of the observations (6 September 2014), see http://www.ladige.it/articoli/2014/09/08/portela-ultimatum-vigili-privati.

${ }^{34}$ The reluctance of law enforcers to intervene against alcohol-related disorder has also been observed with respect to the UK by Jayne, Holloway and Valentine (2006) and by Jayne and Valentine (2016). 
societal attitude was also observed in practice, with passers-by and residents paying little to no attention to the presence of people drinking and adopting nuisance behaviour. ${ }^{35}$

\section{Limitations}

In this article systematic observations have been carried out by one researcher only for seven consecutive evenings. Although observations during such a time-span have allowed the research to cover the drinking habits and practices of people during both weekend and weekdays (an element that was required to test the frequency of alcohol consumption), they may have led to results that may be specific for that particular week. Drinking patterns and alcohol-related disorder may, indeed, vary in other periods of the year. In this study, for example, the observations have been carried out during a period of time when a reduced number of students was present in the two cities. During other periods of the year when the presence of young people in the two localities may be more substantial, drinking patterns and connected disorderly behaviour of this category of people may alter the observed elements and, perhaps, lead to different results. Drinking habits and alcohol-related disorder may also vary according to the season or to the specific weather conditions of the locality. To reduce the impact of some of these limitations, the week(s) selection has been based on days when no special events and celebrations were organised.

In this study only the common symptoms of heavy episodic drinking were taken into consideration to measure the state of public drunkenness, that is, lack of coordination, vomiting, fainting, reaching states of unconsciousness and so forth. In some individuals, however, high levels of inebriation may also translate into feelings of euphoria, excitement and other intense moods which, in practice, may be rather difficult to observe and measure.

With respect to the interviews, they have been carried out only with police agents belonging to two specific police bodies: the Lokale Politie, in Ghent, and the Polizia Locale, in Trento. They are in charge for issuing sanctions for both public drunkenness and for the nuisance behaviour connected with it. Other bodies like the gemeenschapswachten, in Ghent, and the Polizia di Stato and the Carabinieri, in Trento, have only partial sanctioning powers and, therefore, have not been taken into consideration in this paper. Such bodies may also have a different policing approach to public drinking and drunkenness than the one adopted by the two selected law enforcement agencies.

\footnotetext{
${ }^{35}$ In practice, residents may well have called the police. However, it has here been assumed that no complaint was filed, as no (even late) police intervention followed.
} 
In this study, we have attempted to explain or analyse the differences in law enforcement representations of and practices against the nuisance of public drunkenness in the two selected socio-cultural settings in light of the different impact that the aesthetic characteristics or outer appearance/style of individuals and groups were thought to have on police officers there. Other cultural variables not included in this research (like the specific policing cultures, as well as the policing models and practices adopted) may also contribute to explaining the different policing attitudes to the nuisance of public drunkenness in the two selected cities. Moreover, as the number of officers mentioning aesthetic aspects as a factor was limited, we may not exclude the possibility that this aesthetic consideration may not really be representative for the Trento police (not even for Trento Polizia Locale) but rather reflecting some individual biases on the part of the interviewed police officers.

\section{Conclusions}

As the data gathered in this comparative research show, the reality of the nuisance of public drunkenness does not significantly vary in the two nightlife locations of Ghent and Trento, especially not when it comes to considering the levels of intoxication and of disorderly behaviour of drunken people there. What changes is the way in which enforcement actors in these two cities look at public drinking and drunkenness occurring in the selected nightlife areas: while in Ghent they are understood as a rather normal phenomenon (as long as it does not involve the adoption of behaviour that bothers or threatens others) and are overall tolerated by police officers, in Trento they have been regarded as uncivil and attached to the presence of specific groups of people who are differently dressed (e.g., punks, members of the anarchic movements, immigrants and homeless). Specific cultural factors like the importance of aesthetics or of aesthetic styles have been found to play a role in shaping the representation of the nuisance of public drunkenness of some police officers in Trento.

The results of this study also suggest that even when local (punitive) regulations are enacted by municipalities, they may not be enforced in practice or not in all cases. In spite of a different representation of nuisance, police officers in Ghent and Trento apply a similar level of enforcement of local and national regulations against uncivil behaviour (at least, in their proactive interventions). They do so, however, on the basis of a different set of arguments that, depending on context-specific factors, may be normative (as in the case of Ghent) or pragmatic (as in the case of Trento). In Ghent, for example, a low level of police enforcement has been explained by officers in light of their normative attitude to the nuisance of public drunkenness: proactive interventions only target the behaviour that is considered to diverge from the "normal", or from the considered accepted standard of 
drinking. In Trento, by contrast, police officers have justified their reduced (proactive) interventions on the basis of mere pragmatic reasons and constraints.

What the example of Trento also shows is that reactive policing strategies are (at least, partly) influenced by the attitudes that people are perceived to have with respect to a certain phenomenon. More accurately, on the basis of the perceived intolerance of residents, police officers have adopted different strategies for the control of uncivil behaviour in the selected night-time area of Trento (e.g., the application of fines to licensing premises for the uncivil behaviour of their clients).

Societal expectations and attitudes to public drinking (Demant and Landolt, 2013) and, more in general, to uncivil behaviour (Di Ronco, 2014) tend to vary in different areas of the city. Future comparative empirical research should, therefore, also focus on policing strategies towards alcohol-related disorder in different city areas, and inspect whether they are shaped by the perceived (different) attitudes and expectations of people in those areas.

In addition, individual and societal negative attitudes may be learnt by police officers via different channels of communication and, not least, through the media, which may play a crucial role in the construction of incivilities as a "problem". Inspecting the way the media represent the phenomenon of incivilities and its regulation is particularly needed, as it may go a long way in increasing our understanding of the practices of enforcing nuisance regulations in specific social settings.

In conclusion, this comparative research highlights that public drinking and drunkenness (despite in reality not substantially differing between the two cites) may not be always disputed in nightlife locations of different sociocultural settings. They may be seen as a normal phenomenon, which may be very much tolerated by police officers (as the case of Ghent shows), or be considered by them as a deeply problematic activity (as in the case of Trento). The cultural and context-specific factors, including those linked to the cultures of drinking and aesthetics, should therefore also be considered in future (comparative) empirical research to more fully understand and explain the different policing attitudes and responses to alcohol-related disorder in inner-city nightlife areas.

\section{References}

Anderson, P., \& Baumberg, B. (2006). Alcohol in Europe: A Public Health Perspective. A Report for the European Commission. Institute for Alcohol Studies. http://ec.europa.eu/healtheu/doc/alcoholineu_content_en.pdf. Accessed 30 June 2014. 
Calafat, A., Blay, N. T., Hughes, K., Bellis, M., Juan, M., Duch, M. \& Kokkevi, A. (2010). Nightlife young risk behaviours in Mediterranean versus other European cities: Are stereotypes true?. The European Journal of Public Health, 30, 1-5.

Carbonaro, A., \& Quassoli, F. (2013). "Tough on illegal immigrants”. Immigrant control and exclusion in contemporary Italy. Rassegna Italiana di Sociologia, 3, 401-422.

Chatterton, P., \& Hollands, R. (2002). Theorising urban playscapes: Producing, regulating and consuming youthful nightlife city spaces. Urban Studies, 39(1), 95-116.

Chatterton, P., \& Hollands, R. (2003). Urban Nightscapes: Youth Cultures, Pleasure Spaces and Corporate Power. London: Routledge.

Colombo, A. (2013). Foreigners and immigrants in Italy's penal and administrative detention systems. European Journal of Criminology, 10(6), 746-759.

Crawford, A., \& Flint, J. (2009). Urban safety, anti-social behaviour and the night-time economy. Criminology and Criminal Justice, 9(4), 403-413.

Dantzker, M. L., \& Hunter, R. D. (2006). Research Methods for Criminology and Criminal Justice: A Primer. Sudbury: Jones \& Bartlett Learning.

Demant, J., \& Landolt, S. (2013). Youth drinking in public places: the production of drinking spaces in and outside nightlife areas. Urban Studies, 1-15.

Di Ronco, A. (2014). Regulating street prostitution as a public nuisance in the 'culture of consumption': A comparative analysis between Birmingham, Brussels and Milan. In N. Peršak \& G. Vermeulen (Eds.), Rethinking Prostitution: From Discourse To Description, From Moralisation To Normalisation? (pp. 145-171). Antwerp: Maklu.

Easton, M., \& Ponsaers, P. (2010). The view of the police on community policing in Belgian multicultural neighbourhoods. In M. Cools, B. De Ruyver, M. Easton, L. Pauwels, P. Ponsaers, G. Vande Walle, T. Vander Beken, F. Vander Laenen, G. Vermeulen \& G. Vynckier (Eds.), New Empirical Data, Theories and Analyses on Safety, Societal Problems and Citizens' Perceptions (pp. 161-182). Governance of security research papers series 3. Antwerp: Maklu.

Featherstone, M. (2007). Consumer Culture and Postmodernism. London: Sage. 
Felson, R. B., Savolainen, J., Bjarnason, T., Anderson, A. L., \& Zohra, I. T. (2011). The cultural context of adolescents drinking and violence in 30 European countries. Criminology, 49(3), 699-728.

Ferrell, J. (1995a). Culture, crime, and cultural criminology. Journal of Criminal Justice and Popular Culture, $3(2), 25-42$.

Ferrell, J. (1995b). Crimes of style: urban graffiti and the politics of criminality. In J. Ferrell, \& C. R. Sanders (Eds.), Cultural Criminology (pp. 169-189). Boston: Northeastern University Press.

Ferrell, J. (1997). Youth, crime, and cultural space. Social Justice, 24(4), 21-38.

Ferrell, J., \& Sanders, C. (1995). Cultural Criminology. Boston: Northeastern University Press.

Galloway, J., Forsyth, A., \& Shewan, D. (2007). Young people's street drinking behaviour: Investigating the influence of marketing and subculture. Glasgow Centre for the Study of Violence. http://alcoholresearchuk.org/downloads/finalReports/AERC_FinalReport_0044.pdf. Accessed 10 March 2015.

Gilligan, C., Kuntsche, E., \& Gmel, G. (2012). Adolescent drinking patterns across countries: associations with alcohol policies. Alcohol and Alcoholism, 47(6), 732-737.

Gordon, R., Heim, D., \& MacAskill, S. (2012). Rethinking drinking cultures: A review of drinking cultures and a reconstructed dimensional approach. Public Health, 126(1), 3-11

Graham, K., \& Homel, R. (2008). Raising the Bar. Cullompton: Willan Publishing.

Gual, A. (2006). Alcohol in Spain: Is it different? Addiction, 101(8), 1073-1077.

Hale, C., Hayward, K., Wahidin, A., \& Wincup, E. (2005). Criminology. Oxford: Oxford University Press.

Hayward, K., \& Hobbs, D. (2007). Beyond the binge in 'booze Britain': Market-led liminalization and the spectacle of binge drinking. The British Journal of Sociology, 58(3), 437-456.

Hayward, K., \& Yar, M. (2006). The 'chav' phenomenon: Consumption, media and the construction of a new underclass. Crime, Media, Culture, 2(1), 9-28.

Heath, D. B. (1995). International Handbook on Alcohol and Culture. Westport: Greenwood Press. 
Heath, D. B. (1998). Cultural variations among drinking patterns. In M. Grant, \& J. Litvak (Eds.), Drinking Patterns and their Consequences (pp. 103-125). Washington: Taylor and Francis.

Hobbs, D. (2003). The Night-Time Economy. London: Alcohol Concern Research Forum Papers.

Hobbs, D., Hadfield, P., Lister, S., \& Winlow, S. (2003). Bouncers: Violence and Governance in the Night-Time Economy. Oxford: Oxford University Press.

Hobbs, D., Hadfield, P., Lister, S., \& Winlow, S. (2005). Violence and control in the night-time economy. European Journal of Crime Criminal Law and Criminal Justice, 13(1), 89-102.

Hollands, R. (2002). Divisions in the dark: Youth cultures, transitions and segmented consumption spaces in the night-time economy. Journal of Youth Studies, 5(2), 155-171.

Hughes, K., Quigg, Z., Bellis, M. A., van Hasselt, N., Calafat, A., Kosir, M., Juan, M., Duch, M., \& Voorham, L. (2011). Drinking behaviours and blood alcohol concentration in four European drinking environments: A cross-sectional study. BMC Public Health, 11(1), 918.

Järvinen, M., \& Room, R. (2007). Youth Drinking Cultures: European Experiences. Aldershot: Ashgate Publishing.

Jayne, M., \& Valentine, G. (2016). Alcohol-related violence and disorder: New critical perspectives. Progress in Human Geography, 40(1), 67-87.

Jayne, M., Holloway, S. L., \& Valentine, G. (2006). Drunk and disorderly: Alcohol, urban life and public space. Progress in Human Geography, 30(4), 451-468.

Jayne, M., Valentine, G., \& Holloway, S.L. (2008a). Fluid boundaries-British binge drinking and European civility: alcohol and the production and consumption of public space. Space and Polity, 12(1), 81-100.

Jayne, M., Valentine, G., \& Holloway, S.L. (2008b). Geographies of alcohol, drinking and drunkenness: A review of progress. Progress in Human Geography, 32(2), 247-263.

Jayne, M., Valentine, G., \& Holloway, S.L. (2012). What use are units? Critical geographies of alcohol policy. Antipode, 44(3), 828-846.

Jordan, P. W. (2000). Aesthetics and cultural differences. Proceedings of the Human Factors and Ergonomics Society Annual Meeting, 44(32), 6-77. 
Kuntsche, E., Rehm, J., \& Gmel, G. (2004). Characteristics of binge drinkers in Europe. Social Science \& Medicine, 59(1), 113-127.

Landberg, J. (2012). Self-Reported alcohol consumption and the risk of alcohol-related problems: A comparative risk-curve analysis of the 3 Baltic countries, Sweden, and Italy. Alcoholism: Clinical and Experimental Research, 36(1), 113-118.

Lyng, S., \& Bracey, M. (1995). Squaring the one-percent: Biker style and the selling of cultural resistance. In J. Ferrell, \& C. Sanders (Eds.), Cultural Criminology (pp. 235-76). Boston: Northeastern University Press.

MacAndrew, C., \& Edgerton, R. B. (1969). Drunken comportment: A Social Explanation. Chicago: Aldine Publishing.

Mäkelä, P., Gmel, G., Grittner, U., Kuendig, H., Kuntsche, S., Bloomfield, K., \& Room, R. (2006). Drinking patterns and their gender differences in Europe. Alcohol and Alcoholism, 41(1), i8-i18.

Mandelbaum, D. G. (1965). Alcohol and Culture. Current Anthropology, 281-293.

Mastrofski, S. D., Parks, R. B., \& McCluskey, J. D. (2010). Systematic social observation in criminology. In A. R. Piquero, \& D. Weisburd (Eds.), Handbook of Quantitative Criminology (pp. 225-247). New York: Springer.

Masuda, T., Gonzalez, R., Kwan, L., \& Nisbett, R. E. (2008). Culture and aesthetic preference: Comparing the attention to context of East Asians and Americans. Personality and Social Psychology Bulletin, 34(9), 1260-1275.

McLaughlin, E., \& Muncie, J. (2005). The Sage Dictionary of Criminology. London: Sage.

Melossi, D. (2000). The other in the new Europe: Migrations, deviance, social control. In P. Green, \& A. Rutherford (Eds.), Criminal Policy in Transition (pp. 151-166). Oxford: Hart Publishing.

Millie, A. (2008). Anti-social behaviour, behavioural expectations and an urban aesthetic. British Journal of Criminology, 48(3), 379-394.

Nelken, D. (2012). Comparing criminal justice. In M. Maguire (Ed.), Oxford Handbook of Criminology (pp. 139157). Oxford: Oxford University Press.

Parmigiani, F. (2008). Le Implicazioni Costituzionali del Potere Sindacale di Ordinanza. PhD thesis. University of Verona. 
Patton, M. Q. (2002). Qualitative Evaluation and Research Methods. Thousand Oaks: Sage Publications.

Plant, M., \& Miller, P. (2001). Young people and alcohol: An international insight. Alcohol and Alcoholism, $36(6), 513-515$.

Quassoli, F. (2004). Making the neighbourhood safer: Social alarm, police practices and immigrant exclusion in Italy. Journal of Ethnic and Migration Studies, 30(6), 1163-1181.

Quassoli, F. (2013). "Clandestino": Institutional discourses and practices for the control and exclusion of migrants in contemporary Italy. Journal of Language and Politics, 12(2), 203-225.

Reiss, A. J. (1971). Systematic observation of natural social phenomena. In H. L. Costner (Ed.), Sociological Methodology (pp. 3-33). San Francisco: Jossey-Bass.

Richardson, A., \& and Budd T (2003) Young adults, alcohol, crime and disorder. Criminal Behaviour and Mental Health, 13(1), 5-16.

Room, R. (2001). Intoxication and bad behaviour: Understanding cultural differences in the link. Social Science \& Medicine, 53(2), 189-198.

Room, R., \& Mäkelä, K. (2000). Typologies of the cultural position of drinking. Journal of Studies on Alcohol and Drugs, 61(3), 475-483.

Room, R., \& Rossow, I. (2001). The share of violence attributable to drinking. Journal of Substance Use, 6(4), 218-228.

Snacken, S. (2007). Penal policy and practice in Belgium. Crime and Justice, 36(1), 127-215.

Snacken, S., Deltenre, S., Raes, A., Vanneste, C., \& Verhaeghe, P. (1999). Kwalitatief onderzoek naar de toepassing van de voorlopige hechtenis en de vrijheid onder voorwaarden. VUB - NICC. Research report. Brussels.

Tedlock, B. (2003), Ethnography and ethnographic representation. In N.K. Denzin and Y.S. Lincoln (Eds.), Strategies of Qualitative Inquiry. Thousand Oaks: Sage Publications.

Travers, M., Putt, J., \& Howard-Wagner, D. (2013). Special issue on ethnography, crime and criminal justice. Current Issues in Criminal Justice, 25(1): 463-469. 
Weisburd, D., Lawton, B., Ready, J., Rudes, D., Haviland A, Cave, B., \& Nelson, M. (2012). Community Health, Antisocial Behavior and Safety at Street Segments. Grant proposal. National Institute of Health, Washington, US. 